\title{
Working in Inclusive or Non-Inclusive Contexts: Relations Between Collaborative Variables and Special Education Teachers' Burnout
}

\author{
Myriam Squillaci * and Verena Hofmann \\ Department of Special Education, University of Fribourg, Fribourg, Switzerland
}

Over the last two decades, the nature of teachers' work has undergone significant structural changes due to political, social, organizational, technological, and philosophical factors. With the development of inclusive policies, the roles and functions of special education teachers (SETs) have evolved over the years. Inclusive work in general classrooms is often seen as a source of stress for SETs as they may have less autonomy at work, and more complex collaboration than their peers working in special classes. This stress can lead to a burnout syndrome, which is characterized by emotional exhaustion, depersonalization and a lack of personal accomplishment. Less is known about the effects of teaching contexts on the

Edited by: Simone Schoch, Zurich University of Teacher Education, Switzerland

Reviewed by: Gregor James Jenny, University of Zurich, Switzerland Inmaculada Méndez,

University of Murcia, Spain

*Correspondence: Myriam Squillaci myriam.squillaci@unifr.ch

Specialty section:

This article was submitted to Special Educational Needs, a section of the journal Frontiers in Education

Received: 10 December 2020 Accepted: 26 April 2021 Published: 18 May 2021

Citation:

Squillaci M and Hofmann V (2021) Working in Inclusive or Non-Inclusive

Contexts: Relations Between Collaborative Variables and Special

Education Teachers' Burnout.

Front. Educ. 6:640227.

doi: 10.3389/feduc.2021.640227
SETs' health. Therefore, this study aimed to compare the perceived health of a sample of SETs in Switzerland $(N=306)$ working in inclusive contexts $(n=79)$ with those working in non-inclusive contexts $(n=227)$. The sample filled out a self-reported questionnaire measuring personal variables, burnout at work with the Maslach Burnout Inventory, and collaborative variables with the School Quality Survey. Research results show three main findings. 1. Differences in perceived health at work are not significant between the two subgroups. 2. The two subsamples are not exhausted or depersonalized, but present a reduced personal achievement. 3. The collaborationrelated variables exert different effects on the three burnout dimensions.

Keywords: health, burnout, education setting, inclusion, collaboration

\section{INTRODUCTION}

Over the last two decades, the nature of the teachers' work has undergone significant structural changes due both to political, social, organizational, technological, and philosophical factors (Curchod-Ruedi et al., 2013). In this regard, the principle of inclusion of students with special needs education (SNE) in regular classrooms - supported by international conventions, such as the United Nations Convention on the Rights of Persons with Disabilities and the UNESCO Salamanca Statement on Principles, Policy and Practice in SNE - has changed the roles and functions of many school actors. In Switzerland, as in many other countries, public schools must ensure a free and an adequate education in order to support the progress of students with SNE (Sam et al., 2020). However, data from 20 countries reveal that Switzerland is one of the least inclusive countries in Western Europe (European Agency for Development in Special Needs Education, 2010): in most Swiss provinces, the majority of children with SNE attend special schools in institutions, special 
classes in public schools according to their performance levels (European Agency for Development in Special Needs Education, 2012), although since 1980, an inclusive school model has emerged in Switzerland, especially in some provinces as Tessin or Valais. According to data from the Federal Statistic Office, Bless (2017) reported a separation rate in Switzerland close to $3.4 \%$, with great differences from one canton to another $(1.15 \%$ in Obwalden, 3.4\% in Fribourg, $5.78 \%$ in Schaffhausen). In fact, the Swiss education system uses a wide range of options to accomplish its selective mission, which inevitably have consequences on the educational path of the pupils (Bless, 2017). In some cantons, as Fribourg, the implementation of an inclusive school model which led to the creation of an Integration Service to support the schooling of students with SNE (Conférence Suisse des Directeurs de l'Instruction Publique, 2007) didn't take place until 1999. Since then, the number of integrated pupils has continued to increase in Fribourg, like the number of SETs working in inclusive settings.

\section{COMPLEXIFICATION OF THE SPECIAL EDUCATION TEACHERS PROFESSION: A HEALTH RISK?}

By law, teachers must establish individualized educational goals that guide the program the school provides to each pupil (Sam et al., 2020). From a legal point of view, both SETs and regular teachers are responsible for the development of students and their social integration. In this regard, the Profile of Inclusive Teachers, published by the European Agency for Development in Special Needs Education (2012) states that the ability to work with other people and collaborate is an essential requirement for any pedagogue (Milteniene and Venclovaite, 2012). This responsibility is based on collaborative practices that require SETs to adapt to the diversity of their colleagues in terms of inclusive policies (Done and Murphy, 2018). However, this vision of harmonious relations and complementary approaches can be very different depending on the teaching contexts (Boulanger et al., 2012). In fact, the implementation of inclusive policies can interfere with the pedagogical beliefs and values of the different partners, making the roles and functions of SETs so complex that some perceive a loss of their professional identity (Maillard, 2017), leading to premature leaving teaching job and burnout risks. This loss of identity can be explained, among other reasons, by the fact that in mainstream education, curricula and teaching contents are usually not discussed or negotiated with other professionals, the mainstream teacher being generally the sole responsible for his or her class. In contrast, in special education, a large part of the functioning, programs, and contents are interpreted, discussed, negotiated, and decided upon in a multiprofessional approach (Emery, 2016). Thus, working in an inclusive or non-inclusive context cannot be considered without taking into account the different variables related to collaboration. On this topic, some researchers note the difficulties of collaboration in inclusive contexts (Delorme, 2015), which could have an impact on teachers' professional burnout.

\section{COLLABORATION AS RISK FOR TEACHERS' HEALTH: A REVIEW}

If teaching is considered a profession at risk of burnout, this is mainly explained by the high level of relational demand it places on teachers (Betoret, 2009; Gavish and Friedman, 2010; Squillaci, 2020d). The 11th revision of the International Classification of Diseases (ICD-11) defines burnout as the result of a chronic work stress not successfully managed. This syndrome is characterized by three dimensions (World Health Organization [WHO], 2018): 1. Feelings of emotional exhaustion (EE). 2. Feelings of cynicism, depersonalization (D) in relation to work. 3. Lack of personal achievement (PA). This definition is based on the threedimensional burnout model of Maslach (Maslach and Leiter, 2016). A recent literature review ( $k=45$ results studies) revealed worrying percentages of burnout with only $18.4 \%$ of teachers at low risk for $\mathrm{EE}(76,4 \%$ at moderate risk and $5.2 \%$ at high risk), with $38.1 \%$ of teachers at low risk for D $(60.8 \%$ at moderate risk and $1.1 \%$ at high risk) and with only 0.4 of teachers (one study out of 45 results) at low risk for PA (12.7\% at moderate risk and $86.9 \%$ at high risk) (Squillaci, 2020a).

The high proportion of burnout teachers has generated a vast amount of research to identify the risk factors related to this syndrome. To this end, interpersonal variables are studied with specific attention, as studies show that burnout especially affects people in professions with high relational demands (Maslach and Leiter, 2016). The most studied factors regarding collaboration concern the quality of relationships with supervisors, parents, colleagues, and students, as well as role conflicts and lack of decision latitude (Curchod-Ruedi et al., 2009; Özer and Beycioglu 2010; Dyrbye et al., 2014). To our knowledge, there are no metaanalyses or systematic reviews available of the effects of collaboration on health in different contexts (e.g., inclusive vs. non-inclusive). The majority of research in the field tends to focus on teachers' attitudes toward inclusion. For this reason, the present research analyses the effects of the teaching contexts on perceived health by examining the collaborative variables through a systematic review of the literature and an empirical research.

Literature searches adhered to the Preferred Reporting Items for Systematic Reviews and Meta-Analyses (PRISMA). Results of each study were reported by two persons (one author and a master-level student) in order to identify discrepancies. Literature searches of articles published between 1996 and 2016 were conducted in various databases: Medline, Pubmed, Sciencedirect, Springer, Eric, Scopus, ProQuest and PsychInfo. Key terms used in searches included Maslach Burnout Inventory OR MBI AND teachers OR special education teacher OR SETs AND risk factors $O R$ individual $O R$ interpersonal $O R$ organizational. For the systematic review, articles were selected on eight inclusion criteria: 1. Are based on Maslach's model. 2. Use the MBI as a tool to assess burnout. 3. Present quantitative 
results in all three dimensions (EE-D-PA). 4. Include sample teachers or SETs. 5. Report means and standard deviations in the three dimensions of the MBI. 6. Have been published in scientific journals. 7. Include a sample of more than 45 teachers. 8. Include results in link with the selected interpersonal or collaborative variables (school context and lack of control, decision latitude, relationships with parents, pupils, colleagues, school principal). The literature review identified 117 cross-sectional studies, 202 study results of which 74 concerned collaborative variables (80 individual factors and 48 organizational factors). For each study (details available on request), following categories have been reported: authors, date, characteristics of the sample, means and standard deviation in the three burnout dimensions, effects of the independent variables on the three dimensions, $p$-value and effect size (if measured).

Table 1 highlighted 18 study results linked to collaboration and teachers' burnout. School context can generate role conflicts influencing all the three dimensions particularly EE (16 studies out of 18) and D (12 of 18), while PA is affected to a lower extent (8 of 18) (e.g., Doef and Maes, 2002; Wilkerson and Bellini, 2006). According to the review, teaching requires the articulation of several simultaneous roles (instructive, educational, administrative and therapeutic) and carrying several roles simultaneously is considered as a risk factor for burnout (e.g., Kokkinos, 2007; Meng, 2010; Ghorpade et al., 2011). With the increasing number of partners of the educational network, the risk of role conflicts, or even interpersonal conflicts, is greater (e.g., Doef and Maes, 2002; Rascle et al., 2009; Vercambre et al., 2009). Role conflicts arise when faced with contradicting demands, incomplete information, and possible disagreements about work objectives (Billehøj, 2007; Houlfort and Sauvé, 2010). This ambiguity of professional roles influences teachers' health (Wilkerson and Bellini, 2006; Papastylianou et al., 2009). Even if no study has focused on role conflicts by examining inclusive or

TABLE 1 | School context, work control and burnout.

\begin{tabular}{|c|c|c|c|c|}
\hline Study & Sample & EE & D & PA \\
\hline Baran et al. (2010) & 171 & * & & \\
\hline Betoret (2009) & 724 & * & * & * \\
\hline Dorman (2003) (material conditions) & 246 & * & * & * \\
\hline Dorman (2003) (shared value) & 246 & * & * & \\
\hline Ghorpade et al. (2011) & 263 & ** & $\star \star$ & ** \\
\hline Kokkinos (2007) & 447 & ** & & \\
\hline Laugaa et al. (2008) & 410 & $\star \star *$ & $\star \star$ & \\
\hline Meng (2010) (material conditions) & 416 & & $\star \star$ & \\
\hline Meng (2010) (role conflicts) & 416 & ** & $\star \star$ & $\star \star$ \\
\hline Papastylianou et al. (2009) & 562 & * & $\star \star$ & ** \\
\hline Rascle et al. (2009) & 260 & $\star \star$ & * & $\star \star$ \\
\hline Skaalvik and Skaalvik (2009) & 563 & * & & \\
\hline Doef and Maes (2002) & 454 & $\star \star \star$ & & \\
\hline Vercambre et al. (2009) & 2558 & $\star \star$ & $\star \star$ & \\
\hline Wilkerson and Bellini (2006) (number of students) & 78 & & & \\
\hline Wilkerson and Bellini (2006) (role conflicts) & 78 & $\star \star$ & * & ** \\
\hline Wilkerson and Bellini (2006) (ambiguity) & 78 & $\star \star$ & * & \\
\hline Wilkerson and Bellini (2006) (financial ressources) & 78 & * & & * \\
\hline
\end{tabular}

Note. 18 results' studies ( $k=13$ studies; $n=7152$ ) show 16 effects on $E E, 12$ on $D$ and 8 on $P A$. EE = emotional exhaustion; $D$, depersonalization; $P A$, personal achievement. ${ }^{*} \mathrm{p}<$ 0.05. ${ }^{* *} p<0.01$. $^{* * *} p<0.001$. separate contexts, this variable must be taken into account in the assessment of SETs' occupational health. The increasing complexity of the teaching profession, which involves diversified skills adapted to students' needs, is likely to explain teachers' burnout (Betoret, 2009).

Table 2 summarizes 10 study results analyzing links between teachers' health and the lack of participation in decision, a variable related to all the three burnout dimensions. Effects of this variable on EE ( 8 studies out of 10$)$ and D ( 8 studies out of 10$)$ are more pronounced than on PA (5 out of 10 studies). Teachers who perceive a lack of autonomy and participation in decision are more vulnerable to EE (e.g., Doef and Maes, 2002; Kokkinos, 2007) and D (e.g., Näring et al., 2006; Ponnelle, 2008). PA is also affected, but to a lower extent (e.g., Skaalvik and Sidsel, 2007; Rascle et al., 2009). Only one study conducted by Fernet et al. (2012) found no link between decision latitude and at least one of the dimensions of burnout. While research results exist for teachers, they are not available for SETs due to the lack of empirical studies including this population (Antoniou et al., 2013). However, shared decisions appear to be a determinant of teachers' professional health, regardless of the teaching context. Studies of interpersonal variables also place particular emphasis on the support provided by the various educational partners (i.e. pupils, parents, colleagues and school principals).

Table 3 summarizes 13 study results between pupils' relationships and teachers' burnout. Disciplinary problems, disrespect, apathy, low school functioning, learning disabilities and mental illness are major sources of stress for teachers (e.g., Betoret, 2009; Fernet et al., 2012). All three dimensions are affected, in particular PA (11 studies out of 13) but also D (10 out of 13) and EE (9 out of 13). Faced with a demotivated and apathetic audience, teachers expend considerable energy during the day to maintain, as much as possible, a positive classroom climate (Otero et al., 2008). While the quality of teacher-student relationships is one of the most rewarding aspects of the profession, it can also be a source of discouragement and emotionally draining experiences (Betoret, 2009).

Table 4 synthesizes 6 study results analyzing links between parents' relationships and teachers' burnout (Squillaci, 2020b). As evidenced by the results, the three dimensions are affected by conflictual relationships with parents, in particular EE (4 of 6

\begin{tabular}{|c|c|c|c|c|}
\hline Study & $N$ & EE & D & PA \\
\hline Betoret (2009) & 714 & $\star \star$ & * & \\
\hline Fernet et al. (2012) & 806 & & & \\
\hline Kokkinos (2007) & 447 & 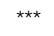 & * & \\
\hline Näring et al. (2006) & 345 & $\star \star$ & 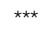 & * \\
\hline Ponnelle (2008) & 191 & & * & * \\
\hline Rascle et al. (2009) & 260 & $\star \star$ & 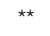 & 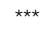 \\
\hline Skaalvik and Skaalvik (2009) & 563 & * & * & ** \\
\hline Doef and Maes (2002) & 454 & 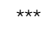 & & \\
\hline Wang et al. (2015) & 559 & $\star \star$ & $\star \star$ & ** \\
\hline Wilkerson and Bellini (2006) & 78 & $\star \star$ & * & \\
\hline
\end{tabular}

Note. 10 results' studies ( $k=10$ studies; $n=4417$ ) show 8 effects on $E E$, 8 on $D$ and 5 on $P A$. EE, emotional exhaustion; $D$, depersonalization; $P A$, personal achievement. * $p<0.0$. ${ }^{* *} p<0.01{ }^{* * *} p<0.001$ 
TABLE 3 | Relationships with pupils and burnout.

\begin{tabular}{|c|c|c|c|c|}
\hline Study & $N$ & EE & D & PA \\
\hline Betoret (2009) & 714 & * & * & * \\
\hline Dorman (2003) (relations) & 246 & & & * \\
\hline Dorman (2003) (discipline) & 246 & & & * \\
\hline Fernet et al. (2012) & 806 & $\star \star \star \star$ & $\star \star$ & 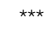 \\
\hline Gavish and Friedman (2010) & 123 & $\star \star$ & $\star \star \star$ & $\star \star$ \\
\hline Grayson and Alvarez (2008) & 320 & $\star \star$ & $\star \star$ & ** \\
\hline Kokkinos (2007) (relations) & 447 & 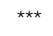 & $\star \star$ & 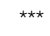 \\
\hline Kokkinos (2007) (behavior) & 447 & $\star \star$ & $\star \star$ & $\star \star$ \\
\hline Meng (2010) & 416 & & $\star \star \star$ & \\
\hline Otero et al. (2008) & 1386 & 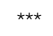 & 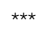 & 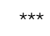 \\
\hline Rascle et al. (2009) & 260 & $\star \star$ & 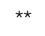 & $\star \star$ \\
\hline Stoeber and Rennert (2008) & 118 & & & \\
\hline Vercambre et al. (2009) & 2558 & $\star \star$ & $\star \star$ & $\star \star$ \\
\hline
\end{tabular}

Note. 13 results' studies ( $k=11$ studies; $\mathrm{n}=7394$ ) show 9 effects on $E E, 10$ on $D$ and 11 on PA. EE, emotional exhaustion; $D$, depersonalization; $P A$, personal achievement. ${ }^{*} p<0.05$. $^{* *} p<0.01$. $^{* * *} p<0.001$.

studies) and PA (4 of 6 studies) as well as D to a lower extent (2 of 6 studies). Authors note that working with parents can be psychologically challenging and is often perceived as a significant stress factor, especially for novice teachers (e.g., Stoeber and Rennert, 2008; Betoret, 2009). Parental pressure has an impact on D and on PA (Stoeber and Rennert, 2008) while lack of parental involvement affects EE (Betoret, 2009). Conflicts with parents, questioning school decisions and practices as well as recourse lead to teacher stress, affecting his or her health (Skaalvik and Skaalvik, 2009). The lack of shared values and goals between parents and teachers hinders collaboration and increases the risk of tension between partners (Grayson and Alvarez, 2008). Positive relationships are considered as protective factors against burnout (Zabel and Zabel, 2002). Despite the lack of research results regarding this variable, its influence must be analyzed for its possible effects on the three dimensions of burnout.

Table 5 summarizes 16 studies that examined the links between interactions with colleagues and teachers' burnout. Relationships with colleagues have an effect on all three dimensions of burnout. The majority of studies (12 of 16) reported associations with EE, 9 with $\mathrm{D}$ and 10 with $p \mathrm{~A}$. Only two studies found no association between these variables (Doef and Maes, 2002; Gavish and Friedman, 2010). Research has shown that the more positive colleagues' supports are perceived, the less exhausted or depersonalized teachers are

TABLE 4 | Relationships with parents and burnout.

\begin{tabular}{lcccc}
\hline Study & N & EE & D & PA \\
\hline Betoret (2009) & 714 & $\star$ & & \\
Gavish and Friedman (2010) & 123 & & & \\
Skaalvik and Skaalvik (2009) & 563 & $*$ & $*$ & $*$ \\
Stoeber and Rennert (2008) & 118 & & & $* \star$ \\
Vercambre et al. (2009) & 2558 & $* \star$ & $* \star$ & $* \star$ \\
Zabel and Zabel (2002) & 298 & $* \star *$ & & $* \star$
\end{tabular}

Note. 6 results' studies ( $k=6$ studies; $\mathrm{n}=4374$ ) show 4 effects on $E E, 2$ on $D$ and 4 on $P A$. EE, emotional exhaustion; $D$, depersonalization; $P A$, personal achievement. * $\mathrm{p}<$ 0.05. ${ }^{* *} p<0.01 .^{* * *} p<0.001$.
TABLE 5 | Relationships with colleagues and burnout.

\begin{tabular}{|c|c|c|c|}
\hline Study & $N$ & EE & D \\
\hline Betoret (2009) & 714 & * & \\
\hline Dorman (2003) & 246 & & \\
\hline Gavish and Friedman (2010) (climate) & 123 & $\star \star$ & \\
\hline Gavish and Friedman (2010) (supports) & 123 & & \\
\hline Ho (2016) & 539 & 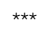 & $\star \star \star \star ~$ \\
\hline Ju et al. (2015) & 307 & $\star \star$ & $\star \star$ \\
\hline Kokkinos (2007) & 447 & $\star \star$ & $\star \star$ \\
\hline Laugaa et al. (2008) & 259 & * & \\
\hline Meng (2010) & 416 & * & $\star \star$ \\
\hline Näring et al. (2006) & 345 & ** & 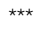 \\
\hline Rascle et al. (2009) & 260 & ** & * \\
\hline Stoeber and Rennert (2008) & 118 & * & \\
\hline Doef and Maes (2002) & 454 & & \\
\hline Vercambre et al. (2009) & 2558 & ** & * \\
\hline Wang et al. (2015) & 559 & & * \\
\hline Zabel and Zabel (2002) & 298 & 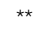 & $\star \star \star \star ~$ \\
\hline
\end{tabular}

Note. 16 results' studies ( $k=15$ studies; $\mathrm{n}=7643$ ) show 12 effects on $E E$, 9 on $D$ and 10 on $P A$. EE, emotional exhaustion; $D$, depersonalization; $P A$, personal achievement. * $\mathrm{p}<$ 0.05. ${ }^{* *} \mathrm{p}<0.01$. $^{* * *} \mathrm{p}<0.001$.

and the more accomplished they are at work (e.g., Ju et al., 2015; Ho, 2016). Studies have noted the negative impact of conflict, peer pressure, and negative work climate within the team on the three dimensions of teachers' burnout (Laugaa et al., 2008; Vercambre et al., 2009). Collegial and regular interpersonal relationships among colleagues are considered protective factors for occupational health (e.g., Stoeber and Rennert, 2008; Betoret, 2009; Baran et al., 2010).

Table 6 presents a synthesis of 10 studies that examined the links between relations with supervisors and teacher's burnout. Among them, 8 established links with at least one of the burnout dimensions, 6 studies with all three dimensions (e.g., Betoret, 2009; Ho, 2016). The effect is confirmed on EE (8 studies out of $10)$, on D (7 studies out of 10) and finally on PA (7 studies out of 10). Only two studies (Doef and Maes, 2002; Gavish and Friedman, 2010) found no relationship between these variables. The level of involvement of school principals, their ability to respond to teachers' needs are considered protective factors against burnout (e.g., Meng, 2010; Fernet et al., 2012). Knowing that the teaching profession requires a certain solitude

TABLE 6 | Relationships with school principals and burnout.

\begin{tabular}{|c|c|c|c|c|}
\hline Study & $N$ & EE & D & PA \\
\hline Betoret (2009) & 714 & * & * & * \\
\hline Fernet et al. (2012) & 806 & $\star \star$ & & ** \\
\hline Gavish and Friedman (2010) & 123 & & & \\
\hline Ho (2016) & 539 & 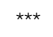 & * & $\star \star$ \\
\hline Meng (2010) & 416 & $\star \star \star \star ~$ & ** & \\
\hline Rascle et al. (2009) & 260 & $\star \star$ & ** & $\star \star *$ \\
\hline Skaalvik and Skaalvik (2009) & 563 & * & * & * \\
\hline Doef and Maes (2002) & 454 & & & \\
\hline Wang et al. (2015) & 559 & $\star \star$ & ** & ** \\
\hline Zabel and Zabel (2002) & 298 & 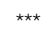 & * & * \\
\hline
\end{tabular}

Note. 10 results' studies ( $k=10$ studies; $\mathrm{n}=4732$ ) show 8 effects on $E E, 7$ on $D$ and 7 on $P A$. EE, emotional exhaustion; $D$, depersonalization; $P A$, personal achievement. * $\mathrm{p}<$ 0.05. ${ }^{* *} p<0.01{ }^{* * *} p<0.001$. 
in terms of pedagogical action, feeling supported by one's superior is considered a bulwark against EE (Squillaci, 2020c). Being supported cognitively and emotionally by one's supervisor is correlated with the three dimensions (Skaalvik and Skaalvik, 2009). Lack of support from superiors appears to be more critical than lack of support from colleagues with respect to teachers' burnout (e.g., Zabel and Zabel, 2002; Wang et al., 2015).

What can we learn from this review? Out of the 74 study results $(\mathrm{k}=24$ studies), 68 established links between the collaborative variables and at least one of the burnout dimensions. Only 7 studies found no effect between these variables. School context and work control are the variables most studied (18 studies), followed by relationships with colleagues (16 studies), with pupils (13 studies), decision latitude and relationships with the school principal (10 studies each), and to a lower extent, relationships with parents (6 studies). It is also interesting to note the proportion of studies showing an impact on all three dimensions. Emotional exhaustion seems to be the dimension most affected by collaborative variables (work control, decision latitude and relationships with school principals), D is more specifically linked to work control and decision latitude and PA to poor relationships with students. While much research has focused on variables in link with collaboration, there is a lack of data on occupational health given the teaching context. To our knowledge, no previous study has assessed the effects of inclusive or noninclusive contexts on the SETs' burnout.

\section{RESEARCH QUESTIONS AND HYPOTHESES}

The present study answers the following research question: How are teaching contexts related to SETs' burnout?

H1: The first hypothesis states that the burnout averages of SETs vary according to their work context (inclusive or separate). This hypothesis has been categorized into sub-hypotheses according to the three dimensions of the Maslach model.

- H1.1: SETs' EE mean values vary according to the context (inclusive or separate).

- H1.2: SETs' D mean values vary according to the context (inclusive or separate).

- H1.3: SETs' PA mean values vary according to the context (inclusive or separate).

$\mathrm{H} 2$ : The second hypothesis states that collaborative variables (decision latitude, relationships with principals, etc.) are differently related to the three burnout dimensions.

- H2.1: EE mean values vary according to work control, decision latitude and relationships with principals.

- H2.2: D mean values vary according to work control and decision latitude.

- H2.3: PA mean values vary according to relationships with students.

\section{METHODS}

\section{Participants}

The research sample included the whole population of SETs working in the French-speaking part of the canton of Fribourg. The Department of Education of the Canton of Fribourg gave its consent for the study and provided a list of all persons working as SETs. All participants were aware of the purpose of the study and they voluntarily agreed to take part with the guarantee that the data processing would be completely anonymous. Participants were not restricted to SETs but also included ordinary teachers and educators currently working with pupils with SNE. The sample includes SETs working either in inclusive contexts ( $n=79 ; 22.9 \%)$ or in non-inclusive contexts $(n=227 ; 65.8 \%)$, 39 respondents $(11.3 \%)$ didn't indicate their work settings. The latter were therefore excluded in the statistical analyses for group comparisons between inclusive and non-inclusive contexts. Most of the participants were women $(n=254 ; 84.8 \%)$, confirming the great feminization of this profession and aged between 31 and 40 years. The majority were university graduates $(>75 \%)$ in the field of special education (Squillaci, 2020d). To better describe the two subsamples of SETs in inclusive and non-inclusive contexts, we added information about the distribution of sex, age, degree of professional qualification, and level of education in the two groups (see Table 7). Chi-Square-Tests revealed that the distribution of the participants' characteristics did not differ significantly between the inclusive and the non-inclusive context.

\section{Measure}

Hypotheses were tested using a self-reporting questionnaire to assess burnout levels in the two subsamples. The questionnaire was presented online using a secure software (EvalandGo). Each SET was instructed to complete the questionnaire thinking about his/her work situation over the last three months, as prescribed by

TABLE 7 | Distribution of participants' characteristics between SETs in inclusive and non-inclusive contexts.

\begin{tabular}{|c|c|c|c|c|c|c|}
\hline \multirow[t]{2}{*}{ Sample characteristic } & \multicolumn{2}{|c|}{ SETs Int } & \multicolumn{2}{|c|}{ SETS $_{\text {Sep }}$} & \multirow[t]{2}{*}{$\chi^{2}$ (df) } & \multirow[t]{2}{*}{$p$} \\
\hline & $N$ & $\%$ & $N$ & $\%$ & & \\
\hline \multicolumn{7}{|l|}{ Sex } \\
\hline Male & 9 & 11.4 & 40 & 17.9 & $1.800(1)$ & 0.180 \\
\hline Female & 70 & 88.6 & 184 & 82.1 & & \\
\hline \multicolumn{7}{|l|}{ Age } \\
\hline 20-30 & 16 & 20.3 & 45 & 19.9 & $0.697(3)$ & 0.874 \\
\hline $31-40$ & 27 & 34.2 & 75 & 33.2 & & \\
\hline $41-50$ & 20 & 25.3 & 67 & 29.6 & & \\
\hline$>50$ & 16 & 20.3 & 39 & 17.3 & & \\
\hline \multicolumn{7}{|l|}{ Degree of qualification } \\
\hline Special education teacher & 54 & 68.4 & 145 & 64.4 & $0.849(2)$ & 0.654 \\
\hline Ordinary teacher & 6 & 7.6 & 25 & 11.1 & & \\
\hline Other educators & 19 & 24.1 & 55 & 24.4 & & \\
\hline \multicolumn{7}{|l|}{ Level of education } \\
\hline University & 60 & 75.9 & 161 & 70.9 & $0.829(2)$ & 0.661 \\
\hline University of teacher education & 9 & 11.4 & 34 & 15.0 & & \\
\hline Other & 10 & 12.7 & 32 & 14.1 & & \\
\hline
\end{tabular}

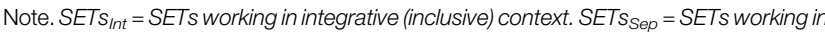
separative context (non-inclusive) context. 
the MBI procedures. A reminder was made after fifteen days. Data were exported to an Excel spreadsheet, and the fully anonymized responses were transferred to SPSS for processing. Part 1 measured sociodemographic variables: age, gender, job title, years' experience, highest level of qualification, specialist training received, type of educational setting, rate at work, type of pupils, etc.).

Part 2 measured burnout through the Maslach Burnout Inventory (MBI). We selected this inventory, as it is the primary instrument used in studies of burnout among teachers and health professionals due to its recognized psychometric and reliability qualities (Kania et al., 2009; Squillaci, 2020c). The MBI consists of 22 items measuring the 3 dimensions of burnout: EE (nine items, such as "I feel emotionally drained from my work; I feel used up at the end of the workday", etc.), D (five items, such as "I worry that this job is hardening me emotionally; I have become more callous toward people since I took this job", etc.), PA (eight items, such as "I feel frustrated by my job; I feel very energic", etc.). Each item is evaluated on a Likert scale that ranges from never to every day. The degree of EE is low if the total score is less than or equal to 17 , it is moderate if the score is between 18 and 29 , it is high if the score is equal to or greater than 30 . The degree of $\mathrm{D}$ is low if the score is less than or equal to 5 , it is moderate if the score is between 6 and 11, it is high if the score is greater than 12. The degree of achievement is low threshold if the score is greater than 40 , it is moderate if the score is comprised between 34 and 39, it is high if the score is less than or equal to 33 (Maslach and Leiter, 2016). The French translation of the MBI was scientifically validated by Dion and Tessier who noted that standardized alpha coefficients are comparable to those reported by Maslach and Jackson, i.e., 0.90 for the EE dimension, 0.64 for $\mathrm{D}$, and 0.74 for PA (Dion and Tessier, 1994). Results in the sample are quite similar to those reported in the French literature, i.e., 0.86 for $\mathrm{EE}$ and 0.82 for PA, but not for D 0.49 (reliability very low).

Part 3 measured the perceived satisfaction at work using the School Quality survey (Bundesministerium für Bildung Wissenschaft und Kultur der Republik Österreich, 1999), an Austrian questionnaire intended for teachers which offers an evaluation of the perceived school quality through 37 items grouped in seven dimensions: work context and control (five items, such as "My school/institution offers good teaching resources"; "I can manage the challenges of my job; "I am satisfied with my timetable", etc.), school principals' relationships (five items such as "My school principal respects my point of view"; "I feel supported by my school principal", etc.), parents' relationships (four items such as "In case of a problem, I am often used as a scapegoat"; "Parents do not sufficiently recognize our efforts", etc.), pupils' relationships (five items such as "I have good personal relationships with my students"; "Relationships with students give me a lot of pleasure", etc.), colleagues' relationships (seven question such as "I receive good advice from my colleagues", "I have several friends among my colleagues", etc.), teaching activity (six items such as "I like teaching in this school", etc.), global teaching satisfaction (five items such as "On the whole, the advantages are predominant in my school", etc.). Responses were collected on a Likert scale with respectively two levels of agreement and two levels of disagreement. Results in the sample reported standardized alpha coefficients 0.70 for work control, 0.42 for school principals, 0.56 for pupils, 0.66 for parents, 0.51 for colleagues (reliability very low). Items of this questionnaire were used as independent variables to measure satisfaction with collaborative variables and their effects on burnout.

\section{Procedure}

For the first hypothesis, the research plan includes three dependent variables (EE, D, PA) and one independent variable (inclusive or non-inclusive context). For the second hypothesis, the research plan includes three dependent variables (EE, D, PA) and five independent variables (work control, relationships with pupils, parents, colleagues and school principal). In order to verify the SETs health according to their work context, we analyzed how these five collaborative variables are linked to EE, D, and PA.

\section{Statistical Analyses}

The data were recorded using Microsoft Excel and statistical analyses were carried out with the programs SPSS software (version 27). First, descriptive statistics were performed for each dimension and a Chi-square test indicated the distribution of the frequencies between the two subgroups. We used the mean values and distributions of data to create a ranked list of perceived SETs' health at work. Then, in order to test the hypothesis related to teaching contexts, the means of both subsamples were calculated and subjected to a two-tailed $t$-test. In a third step, the effects of all collaborative variables were tested simultaneously in multiple regression models (separately for the 3 burnout domains) with continuous and categorical predictors. In these analyses, we also controlled for subgroups (inclusive vs. non-inclusive). In case assumptions regarding data distribution were not met, tests with robust standard errors were used to avoid biased results.

\section{RESULTS}

Table 8 presents the distribution of SETs scores on the three dimensions of the burnout.

With respect to EE, the percentages of SETs at low risk for EE score present no significant difference between the two subgroups $\left(\chi^{2}=5.728 ; \mathrm{df}=3 ; p=0.126\right)$. Regarding $\mathrm{D}$, the percentages at low risk do not differ significantly for both subgroups $\left(\chi^{2}=2.521 ; \mathrm{df}=3 ; p=0.471\right)$. Outcomes indicate that the vast majority of SETs do not appear depersonalized at work. Concerning PA, the percentages of SETs at low risk for PA present no significant difference according to teaching contexts $\left(\chi^{2}=5.418 ; \mathrm{df}=3 ; p=0.144\right)$. These data display that the samples present a moderate risk for PA, more particularly for SETs working in integration (only 38\% feeling selfaccomplished at work). 
TABLE 8 | Distribution of SETs in the three dimensions of the MBI.

\begin{tabular}{|c|c|c|c|c|c|}
\hline \multirow[t]{2}{*}{ Dimension } & \multirow{2}{*}{$\begin{array}{l}\text { Levels of } \\
\text { burnout }\end{array}$} & \multicolumn{2}{|c|}{ SETS $_{I n t}$} & \multicolumn{2}{|c|}{ SETs $_{\text {Sep }}$} \\
\hline & & $N$ & $\%$ & $n$ & $\%$ \\
\hline \multirow[t]{3}{*}{ EE } & Low risk & 48 & 62.3 & 151 & 70.9 \\
\hline & Moderate risk & 26 & 33.8 & 48 & 22.5 \\
\hline & High risk & 3 & 3.9 & 14 & 6.6 \\
\hline \multirow[t]{3}{*}{$D$} & Low risk & 73 & 94.8 & 195 & 91.1 \\
\hline & Moderate risk & 4 & 5.2 & 18 & 8.4 \\
\hline & High risk & 0 & 0 & 1 & 0.5 \\
\hline \multirow[t]{3}{*}{ PA } & Low risk & 29 & 37.7 & 100 & 47.6 \\
\hline & Moderate risk & 31 & 40.3 & 64 & 30.5 \\
\hline & High risk & 17 & 22.0 & 46 & 21.9 \\
\hline
\end{tabular}

Note. EE, emotional exhaustion; D, depersonalization; PA, personal achievement. SETs Int = SETS working in integrative context; SETs Sep $=$ SETs working in separative context (non-inclusive) context.

\section{Special Education Teachers' Burnout in Inclusive or Non-inclusive Settings}

In order to verify $\mathrm{H} 1$, the data of the two subgroups were submitted to an independent sample two-tailed $t$-test.

Table 9 illustrates that means between SETs working in inclusive settings $\left(\mathrm{SETs}_{\text {Int }}\right)$ and SETs working in non-inclusive settings $\left(\mathrm{SETs}_{\text {Sep }}\right)$ present no difference in the three burnout dimensions. Results indicate neither significant difference for EE $(t=-1.222 ; \mathrm{df}=288 ; p=0.222)$ nor for $\mathrm{D}$ for the two subsamples $(t=0.524 ; \mathrm{df}=288 ; p=0.601)$. Regarding PA, analyses also show no statistically significant difference between the two samples $(t=1.073 ; \mathrm{df}=288 ; p=0.284)$. The means indicate that SETs seem to be neither exhausted nor depersonalized but at moderate risk for $p$ A. This signifies that SETs seem to have a positive view of their health at work, regardless of the teaching context (inclusive or non-inclusive).

\section{Effects of Collaboration on Perceived Health}

In order to verify if there is a difference in collaborative variables according to the work context, we first estimated the Pearson correlation coefficients between the MBI scale and the School Quality survey (see Table 10). The data of the two subgroups were then submitted to an independent two-tailed $t$-test (see Table 11).

Table 11 shows that among the collaborative variables, the least positively perceived variable is the relationships with parents (rated on average as "quite good"). The means of SETs working in special classes are significantly lower than those of teachers working in integration $(t=-2.125 ; \mathrm{df}=285 ; p=0.034)$ which

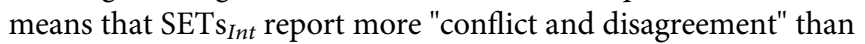
SETs $_{\text {Sep. }}$. Relationships with colleagues are evaluated positively in both subgroups and analyses reveal no statistical differences $(t=$ $-1.335 ; \mathrm{df}=285 ; p=0.183)$. Relationships with pupils are assessed very positively by both subgroups ( $t=1.196$; $\mathrm{df}=$ $285 ; p=0.233$ ) and the context (inclusive or not inclusive) does not affect the means. Finally, relations with the school principal also present levels of satisfaction considered as "good" for teachers working in separate contexts and even as
TABLE 9 | Differences in means in the three dimensions of burnout between the two subgroups.

\begin{tabular}{|c|c|c|c|c|c|c|}
\hline \multirow[t]{2}{*}{ Dimension } & \multicolumn{2}{|c|}{ SETS $_{I n t}$} & \multicolumn{2}{|c|}{ SETs $_{\text {Sep }}$} & \multirow[t]{2}{*}{$t(288)$} & \multirow[t]{2}{*}{$p$} \\
\hline & $M$ & $S D$ & $M$ & $S D$ & & \\
\hline EE & 15.82 & 7.38 & 14.57 & 7.80 & -1.222 & 0.222 \\
\hline D & 1.83 & 2.06 & 1.99 & 2.19 & 0.524 & 0.601 \\
\hline PA & 37.30 & 5.96 & 38.20 & 6.42 & 1.073 & 0.284 \\
\hline
\end{tabular}

Note. EE, emotional exhaustion; $D$, depersonalization; $P A$, personal achievement. SETs $s_{\text {Int }}$ = SETs working in integrative context; SETS $s_{\text {Sep }}=$ SETS working in separative context (non-inclusive).

"very good" for teachers working in integration $(t=-4.204 ; \mathrm{df}=$ $285 ; p=0.000$ ). In terms of work control (satisfaction with the context and role conflicts), both subgroups report a fairly good level of satisfaction, with no statistical difference in the means between the two subgroups $(t=-0.700$; $\mathrm{df}=285 ; p=0.484)$.

In order to verify $\mathrm{H} 2$, multiple regression models were calculated that considered all collaborative variables simultaneously to predict each of the three burnout dimensions. Since there were differences between subgroups (inclusive vs. non-inclusive work context) in some of the collaboration-related variables, subgroup membership was added to the multiple regression models as a control variable.

Table 12 first shows the results regarding EE. As can be seen, parents' relations $(B=0.26, S E=0.09, p=0.002)$, pupils' relations $(B=0.30, S E=0.13, p=0.019)$, work control $(B=-0.76, S E=$ $0.14, p<0.001)$, and colleagues' relations $(B=0.45, S E=0.17, p=$ $0.010)$ exhibited significant effect on SETs EE with small to medium effect sizes $\left(\eta^{2}=0.03-0.05\right)$. That is, problematic relationships with parents or colleagues were associated with higher EE. The same is true for positive relationships with pupils. On the other hand, greater satisfaction with control at work went along with less EE. In addition, there were significant effects of parents' relations $(B=-0.29, S E=0.09, p=0.001)$, pupils' relations $(B=0.32, S E=0.11, p=0.003)$, and work control $(B=0.53, S E=0.14, p<0.001)$ on PA, indicating small effects $\left(\eta^{2}\right.$ $=0.02-0.09$ ). While bad relationships with parents were related to less PA, positive relationships with pupils and greater satisfaction with work were positively associated with $p$ A. Related to D, only poor relationships with parents were predictive of higher scores in $\mathrm{D}(B=0.10, S E=0.05, p=0.033)$. However, the effect size was small $\left(\eta^{2}=0.02\right)$.

\section{DISCUSSION}

The purpose of this study was to compare the occupational health of SETs working in inclusive or non-inclusive contexts while identifying collaborative variables related to burnout dimensions in this profession.

\section{Burnout Levels According to the Settings}

The first hypothesis assumed the existence of a difference in perceived work health between the two subgroups, arguing that inclusive contexts implied more difficulties in collaboration. The 
TABLE 10 | Correlations between variables used for hypotheses tests.

\begin{tabular}{|c|c|c|c|c|c|c|c|c|c|c|c|}
\hline Variable & $M(S D)$ & $\%$ & 1 & 2 & 3 & 4 & 5 & 6 & 7 & 8 & 9 \\
\hline 1. EE & $1.65(0.85)$ & - & - & $0.39^{\star \star \star}$ & $-0.26^{\star \star \star}$ & $-0.15^{\star \star}$ & $0.22^{\star \star \star}$ & 0.09 & $-0.31^{\star \star}$ & $0.17^{\star \star}$ & 0.07 \\
\hline 2. $D$ & $0.40(0.44)$ & - & & - & $-0.31^{\star \star \star}$ & $-0.15^{\star \star}$ & $0.15^{\star \star}$ & -0.11 & $-0.18^{\star \star}$ & 0.07 & -0.03 \\
\hline 3. PA & $4.72(0.82)$ & - & & & - & $0.21^{\star \star \star}$ & $-0.25^{\star \star \star}$ & $0.18^{\star}$ & $0.28^{\star \star \star}$ & -0.08 & -0.07 \\
\hline 4. School principal's relations & $1.88(0.43)$ & - & & & & - & -0.06 & 0.02 & $0.41^{\star \star \star}$ & -0.09 & $0.20^{\star \star}$ \\
\hline 5. Parents'relations & $0.92(0.55)$ & - & & & & & - & 0.00 & -0.07 & 0.09 & $0.13^{\mathrm{C}}$ \\
\hline 6. Pupils' relations & $2.09(0.39)$ & - & & & & & & - & $0.16^{\star \star}$ & $0.20^{\star \star}$ & -0.07 \\
\hline 7. Work control & $2.16(0.36)$ & - & & & & & & & - & 0.04 & $0.13^{*}$ \\
\hline 8. Colleagues' relations & $1.35(0.29)$ & - & & & & & & & & - & 0.08 \\
\hline 9. SETs $\mathrm{sep}_{\text {(compared to SETs Int }}$ ) & - & 65.8 & & & & & & & & & - \\
\hline
\end{tabular}

Note. EE, emotional exhaustion; D, depersonalization; $P A$, personal achievement. SETs Int $_{1}=S E T$ s working in integrative context; SETs Sep $=S E T s$ working in separative context (noninclusive). ${ }^{*} \mathrm{p}<0.05$. $^{* *} \mathrm{p}<0.01$. $^{* * *} \mathrm{p}<0.001$

results showed that the burnout mean scores indicated no significant difference between the two subgroups and low risk for $\mathrm{EE}$ and $\mathrm{D}$, but moderate risk for $p \mathrm{~A}$. The majority of SETs reported low risk for $\mathrm{EE}$ regardless of their teaching context $\left(\mathrm{SETs}_{\text {Int }}=62 \%\right.$; SETs $\left.\mathrm{s}_{\text {Sep }}=71 \%\right)$. This low percentage of exhausted teachers doesn't corroborate research in the field, as literature mentioned much higher proportion of teachers with moderate or high risk for EE (e.g., Kokkinos, 2007; Laugaa et al., 2008; Arquero and Donoso, 2013). Results also indicated no difference between the two subgroups concerning the D dimension $\left(M_{i n t}=1.83\right.$; T2: $M_{\text {Sep }}=1.99$ ), and the averages indicated very low $\mathrm{D}$ scores which seems to indicate that the sample did not experience depersonalization at work, in both inclusive and non-inclusive contexts. Outcomes showed that SETs present a moderate risk in PA $\left(\mathrm{M}_{\text {Int }}=37.30 ; \mathrm{M}_{\text {Sep }}=38.20\right)$. These results may perhaps be related to the lack of professional perspectives inherent in the profession of SETs. However, according to MBI standards, the fact of being at a moderate risk for PA is not sufficient to assert that teachers are in burnout, if the two other dimensions remain in low range.

These data highlight several elements. First, it is encouraging that inclusive and non-inclusive contexts seem to offer working conditions that preserve the perceived health of the SETs. In both settings, working conditions appear to be similar enough, which contradicts the statements by some authors who highlighted the difficulties of collaboration in inclusive contexts (Delorme 2015). Second, the averages of the two subgroups present low risk for $\mathrm{EE}$ and $\mathrm{D}$ but moderate risk for $p \mathrm{~A}$. These results are not in line with those found in the literature, as the majority of research indicates moderate or high risk for EE (see the systematic review of Squillaci, 2020a). For

TABLE 11 | Comparison of collaborative variables means in the two subgroups.

\begin{tabular}{|c|c|c|c|c|c|c|}
\hline \multirow[t]{2}{*}{ Variable } & \multicolumn{2}{|c|}{ SETS $_{\text {Int }}$} & \multicolumn{2}{|c|}{ SETs $_{\text {Sep }}$} & \multirow[t]{2}{*}{$t(285)$} & \multirow[t]{2}{*}{$p$} \\
\hline & $M$ & $S D$ & $M$ & $S D$ & & \\
\hline School principal's relations & 2.05 & 0.29 & 1.86 & 0.45 & -4.204 & 0.000 \\
\hline Parents'relations & 1.03 & 0.54 & 0.87 & 0.55 & -2.125 & 0.034 \\
\hline Pupils' relations & 2.05 & 0.36 & 2.11 & 0.39 & 1.196 & 0.233 \\
\hline Colleagues' relations & 1.40 & 0.26 & 1.35 & 0.29 & -1.335 & 0.183 \\
\hline Work control & 2.08 & 0.58 & 2.02 & 0.56 & -0.700 & 0.484 \\
\hline
\end{tabular}

PA, both subgroups presented moderate scores (with no significant difference between the two groups), but when these data are linked to those reported in the literature, de facto weighting is necessary, as the vast majority of research reports high risk scores for teachers' PA (only one study out of 45 reported low risk score for PA). On this topic, the frequent use of the MBI in research cannot hide the disagreements on the relationships between its three dimensions. Several researchers note that PA seems to evolve in a different way with respect to EE and D (Zawieja and Guarnieri, 2013; Squillaci, 2020d). Finally, these results are not really unexpected, since the resources allocated to support children with SEN are counted

TABLE 12 | Multiple regression analyses to predict the three dimensions of burnout by all collaboration-related variables, controlling for subgroup membership.

\begin{tabular}{|c|c|c|c|c|c|}
\hline Variable & $B$ & SE B & $t$ & $p$ & $\eta^{2}$ \\
\hline \multicolumn{6}{|l|}{ EE } \\
\hline Intercept & 2.12 & 0.47 & 4.52 & $<0.001$ & \\
\hline School principal's relations & -0.07 & 0.12 & -0.53 & 0.596 & 0.001 \\
\hline Parents'relations & 0.26 & 0.09 & 3.12 & 0.002 & 0.03 \\
\hline Pupils' relations & 0.30 & 0.13 & 2.35 & 0.019 & 0.02 \\
\hline Work control & -0.76 & 0.14 & -5.30 & $<0.001$ & 0.09 \\
\hline Colleagues' relations & 0.45 & 0.17 & 2.60 & 0.010 & 0.02 \\
\hline SETs Sep $_{\text {(compared to SETs }}$ Int $)$ & -0.20 & 0.11 & -1.79 & 0.075 & 0.01 \\
\hline \multicolumn{6}{|l|}{ - } \\
\hline Intercept & 0.80 & 0.25 & 3.14 & 0.002 & \\
\hline School principal's relations & -0.10 & 0.07 & -1.58 & 0.116 & 0.01 \\
\hline Parents'relations & 0.10 & 0.05 & 2.14 & 0.033 & 0.02 \\
\hline Pupils' relations & -0.12 & 0.07 & -1.71 & 0.088 & 0.01 \\
\hline Work control & -0.10 & 0.08 & -1.31 & 0.191 & 0.01 \\
\hline Colleagues' relations & 0.10 & 0.09 & 1.10 & 0.270 & 0.004 \\
\hline SETs $s_{S e p}$ (compared to SETs $s_{\text {Int }}$ ) & 0.03 & 0.06 & 0.52 & 0.605 & 0.001 \\
\hline \multicolumn{6}{|l|}{$\mathrm{PA}^{\mathrm{a}}$} \\
\hline Intercept & 3.05 & 0.49 & 6.17 & $<0.001$ & \\
\hline School principal's relations & 0.19 & 0.13 & 1.47 & 0.143 & 0.01 \\
\hline Parents'relations & -0.29 & 0.09 & -3.34 & 0.001 & 0.04 \\
\hline Pupils' relations & 0.32 & 0.11 & 3.02 & 0.003 & 0.03 \\
\hline Work control & 0.53 & 0.14 & 3.82 & $<0.001$ & 0.05 \\
\hline Colleagues' relations & -0.23 & 0.19 & -1.23 & 0.222 & 0.01 \\
\hline SETs $s_{S e p}$ (compared to SETs $s_{\text {Int }}$ ) & 0.13 & 0.10 & 1.24 & 0.214 & 0.01 \\
\hline
\end{tabular}

Note. EE, emotional exhaustion; $D$, depersonalization; PA, personal achievement. ${ }^{a}$ Since the assumption of homoscedasticity was not met for $P A$, the results of parameter estimate with robust standard errors are reported here. 
according to the severity of each child's disability, regardless of the context in which he or she attends school. In Switzerland, the State allocates significant budgets to support pupils, and this factor can probably explain the good health perceived by both subgroups (Squillaci, 2020d). As it stands, the hypothesis that the teaching context (inclusive or non-inclusive) is related to the average of at least one of the three dimensions can be rejected.

\section{Collaborative Variables and Special Education Teachers' Burnout}

The second hypothesis evaluated collaborative variables in order to test their relations on the three dimensions of burnout. Outcomes highlighted that parents' relations, pupils' relation, colleagues' relations, and work control exhibited significant links on SETs' EE with small to medium effect sizes.

In terms of relationships with pupils, results indicated that both subgroups are very satisfied with these relationships, whether in an inclusive or non-inclusive setting, with scores representing no significant difference between the two subsamples. Analyses highlighted that student relationships are more specifically related to $\mathrm{D}$ and $p \mathrm{~A}$. These results are supported by the vast majority of studies in the literature review that notes the effects of this variable on D as found in 9 out of 13 studies (e.g., Otero et al., 2008; Gavish and Friedman, 2010) and on PA as reported by 11 out of 13 studies (e.g., Rascle et al., 2009; Vercambre et al., 2009). EE was not associated with pupils' relationships, which was supported by 4 out of 13 studies (e.g., Dorman, 2003; Stoeber and Rennert, 2008). Researchers highlight the links between behavioral disorders and disciplinary management on this variable (e.g., Dorman, 2003; Kokkinos, 2007).

With respect to the relationships with pupils' parents, results showed that both subgroups were satisfied with this variable although if SETs $\mathrm{Snt}_{\text {Int }}$ assessed these relationships somewhat less positive than $\mathrm{SETs}_{\text {Sep }}$ (negatively worded items) (Squillaci, 2020b). This is certainly related to the fact that SETs sep work very closely with parents, whereas the key referent of an integrated child is mainly the regular teacher. Outcomes showed that relationships with parents are more specifically related to $\mathrm{EE}$ and $p \mathrm{~A}$. These results are supported by 4 studies (out of the 6 identified) from the literature review for EE (e.g., Zabel and Zabel, 2002; Vercambre et al., 2009) and PA (e.g., Stoeber and Rennert, 2008; Vercambre et al., 2009). Depersonalization was not affected by this variable, which is consistent with 4 out of 6 studies (e.g., Betoret, 2009; Gavish and Friedman, 2010). More generally, these results suggest that the relationship between parents and teachers is good, and this is probably due to respect for each other's roles and functions. Indeed, as Maubant and Leclerc (2008) note, an effective partnership cannot be improvised, as it call into question the role and place of each partner.

With respect to colleagues' relationships, results illustrate that both subgroups were fairly satisfied with peer relationships without significant differences according to the work context. In addition, results showed that co-worker relationships affected only the PA dimension. These data are supported by 10 out of 16 studies (e.g., Rascle et al., 2009; Ho, 2016). The fact that EE was not associated with these relationships is supported by only 4 out of 16 studies (e.g., Doef and Maes, 2002; Dorman, 2003). The absence of an effect on D is documented in 7 out of 16 studies from the review (e.g., Laugaa et al., 2008; Betoret, 2009). Results suggest that teachers are able to adjust to the diversity of their colleagues even in inclusive contexts (Done and Murphy, 2018). Training probably plays a role in the positive perception of relationships among colleagues. The vast majority of the sample has an academic background that includes a significant number of modules on partnership and allows trainee teachers to experience different teaching contexts.

With respect to relationships with school principals, results indicated that both subgroups were very satisfied with these relationships. Data further showed differences between teaching contexts: inclusive teachers were more satisfied than those working in non-inclusive settings. These data must be related to the particular context of inclusive teachers in the French-speaking part of the canton of Fribourg. Teachers all depended on the same service, which was keen to maintain weekly contact with each teacher and create a unit of belonging between the SETs themselves and the principal. However, the SETs $s_{\text {Sep }}$ also showed good levels of satisfaction, despite this statistical difference between the subgroups. Outcomes further revealed that relationships with school principals were associated with all three burnout dimensions. These findings are confirmed by the vast majority of the studies in the literature review that highlight the effects of collaboration with school principals on EE, as shown in 8 out of 10 studies (e.g., Zabel and Zabel, 2002; Meng, 2010), on D as shown in 7 studies (e.g., Betoret, 2009; Ho, 2016) and on PA as shown in 7 studies (e.g., Skaalvik and Skaalvik, 2009; Fernet et al., 2012). Researchers note the role of principal support as an important factor influencing teachers' perceived health at work as corroborated by various research in the field (Squillaci, 2020c). Feeling supported by the school principal is a variable that likely explains the perceived good health of both subgroups.

In addition, greater satisfaction with school context and work control, was related to less EE and more PA (no effect on D). These results are in line with 16 out of 18 studies in the EE literature review (e.g., Wilkerson and Bellini, 2006; Ghorpade et al., 2011), 12 out of 18 studies for D (e.g., Laugaa et al., 2008; Meng, 2010) and 8 out of 18 studies for PA (e.g., Papastylianou et al., 2009; Rascle et al., 2009). These feelings are likely related to an excess of responsibilities in daily work, the articulation of several roles that exceed expectations and the articulation required for team work in both contexts. These data emphasized that special education requires the articulation of several simultaneous roles (instructive, educational, administrative and therapeutic, etc.) and these cumulative roles may affect workplace health. However, it is important to remember that, in both subsamples, the means remain within the correct thresholds for the majority of SETs.

Taken together, results suggest that the hypotheses related to the collaboration are partially confirmed. In summary, in both subsamples, SETs' EE is related to work control, relationships with parents and colleagues, while the results of the review 
identified links with work control, decision latitude and relationships with principals; $\mathrm{D}$ is associated with work control, relationships with students and school principals, while findings of the review noted links with work control and decision latitude and PA is related to work control, relationships with students, parents, colleagues and school principal, while the outcomes of the review identified links with the students' relationships. Variables that affect most dimensions are work control and leadership relationships (e.g., respond to SETs' expectations, deal with complex situations, coordinate the different educational partners' resources and build up a trusting climate in the school) (Squillaci, 2020c).

\section{CONCLUSION}

Healthy and inclusive schools? A difficult question to which this article has attempted to answer through a systematic review and an empirical research. Results suggest a positive perception of the health of SETs regardless of the teaching context, as both subgroups do not appear to be exhausted or depersonalized. Thus, whether in an integrated or non-integrated context, the resources available appear to be sufficient to allow a positive perception of health at work. In order to provide external validity to the study, these outcomes were presented to school authorities, school principals and, most importantly, to the SETs themselves. All noted that the study results reinforced their perceptions and opinions on their work experiences. These data tend to illustrate that special education allows professionals to live in healthy conditions, an encouraging sign, as research indicates the positive impact of teachers' health not only on students' wellbeing, but also on their school performances (see Emilie et al., 2018).

\section{STRENGTHS, LIMITATIONS, AND FUTURE RESEARCH DIRECTIONS}

Interpretation of these results must take into account the strengths and limitations of the study (Squillaci, 2020d; Squillaci, 2020b). One of the first limitations is related to the fact that the perceived health at work was measured by self-administered questionnaires. This procedure does not take into account all the factors that compose teachers' perceived health. A second limitation is related to the representativeness of the sample, the compared samples are very heterogeneous in number. Despite a proportionally high rate of respondents (more than $60 \%$ ), the question of whether those affected by burnout participated in the study remains open. A methodological limitation relates to the reliability of the depersonalization burnout dimension and of the School Quality survey, which were very low in the present study. Further studies are needed that make adjustments in the French translation and reevaluate the factor structure and reliability of these two scales. However, these limitations are offset by several strengths. First, this research presents an original approach by combining a systematic review of the literature with an empirical study, in order to better understand SETs' burnout in relation to collaborative variables. Second, this study is a necessary topic because there is hardly any research on teachers dedicated to special education. Third contribution of this research is that it counteracts the idea that SETs are an $a$ priori population in burnout (Squillaci, 2020d). The good perceived health of both sub-samples is probably related to the generally advantageous working conditions in Switzerland. Caution should therefore be exercised in generalizing these results to other countries, as Switzerland is a country with a substantial education budget. Our findings indirectly suggest that the state has a key role in preventing burnout by allocating sufficient financial resources to maintain the health of SETs (Squillaci, 2020d). In light of these findings, future research must not disregard interventions focused on promoting a healthy and constructive partnership climate between all the actors in the school system. Additional research in this field is still needed for at least two main reasons: after data collection, the integration service has been disbanded and for the past year, the SETs are under the supervision of regular school principals. Therefore, it would be interesting to assess the burnout of SETs in relation to this new situation. For the past year as well, COVID-19 has also been pressing heavy demands on SETs who have seen their work and roles evolve over long periods of time. As a result, teachers' occupational health needs to be assessed regularly in order to prevent the apparition of burnout.

\section{DATA AVAILABILITY STATEMENT}

The raw data supporting the conclusions of this article will be made available by the authors, without undue reservation.

\section{ETHICS STATEMENT}

The authorities gave written informed consent for the study. The participants were informed about the survey and free to participate. By participating, they gave their implicit agreement to the research and to the processing of their confidential data. At the end of the questionnaire, they clicked on a section approving participation in the research with the guarantee of confidential treatment of their data.

\section{AUTHOR CONTRIBUTIONS}

The authors agree to be accountable for the content of the work.

\section{ACKNOWLEDGMENTS}

This research has been authorized by the Fribourg Department of Education. 


\section{REFERENCES}

Antoniou, A.-S., Ploumpi, A., and Ntalla, M. (2013). Occupational Stress and Professional Burnout in Teachers of Primary and Secondary Education: The Role of Coping Strategies. Psych 04 (03), 349-355. doi:10.4236/psych.2013. 43a051

Arquero, J. L., and Donoso, J. A. (2013). Docencia, investigación y burnout: el síndrome del quemado en profesores universitarios de Contabilidad. Revista de Contabilidad 16 (2), 94-105. doi:10.1016/j.rcsar.2013.04.001

Baran, G., Bıçakçı, M. Y., İnci, F., Öngör, M., Ceran, A., and Atar, G. (2010). Analysis of Burnout Levels of Teacher. Proced. - Soc. Behav. Sci. 9, 975-980. doi:10.1016/j.sbspro.2010.12.270

Betoret, F. D. (2009). Self-efficacy, School Resources, Job Stressors and Burnout Among Spanish Primary and Secondary School Teachers: a Structural Equation Approach. Educ. Psychol. 29 (1), 45-68. doi:10.1080/01443410802459234

Billehøj, P. H. (2007). Rapport Sur L'enquête Du CSEE Sur Le Stress Au Travail Des Enseignants. Bruxelles: Comité Syndical Européen.

Bless, G. (2017). "Irreguläre Schullaufbahnen Im Rahmen Der Obligatorischen Schule Und Forschungsergebnisse Zur Klassenwiederholung," in Bildungsverläufe von Der Einschulung Bis in Den Ersten Arbeitsmarkt (Wiesbaden: Springer Fachmedien Wiesbaden), 39-57. doi:10.1007/978-3658-16981-7_3

Boulanger, D., Larose, F., Larivée, S. J., Couturier, Y., Mérini, C., Blain, F., Cusson, V., Moreau, D., and Grenier, N. (2012). "Critique Des Fondements et Usages de l'écosystémie Dans Le Domaine Du Partenariat École-Famille-Communauté : Application d'une Perspective Contextuelle et Socioculturelle Dans Le Cadre Du Programme Famille, École, Communauté, Réussir Ensemble. Serv. Soc. 57 (2), 129. doi:10.7202/1006300ar

Bundesministerium für Bildung Wissenschaft und Kultur der Republik Österreich (1999). Schulqualität Und Nachhaltige Entwicklung. Wien.

Conférence Suisse des Directeurs de l'Instruction Publique (CDIP) (2007). Commentaire Des Dispositions Sur l'Accord Intercantonal Sur La Collaboration Dans Le Domaine de La Pédagogie Spécialisée. Berne.

Curchod-Ruedi, D., Doudin, P.-A., and Peter, V. (2009). Le Soutien Social Comme Facteur de Protection Du Burnout Des Enseignants.. Prismes 10, 55-58.

Curchod-Ruedi, D., Ramel, S., Bonvin, P., Albanese, O., and Doudin, P.-A. (2013). De l'intégration à l'inclusion scolaire: implication des enseignants et importance du soutien social. Alter 7 (2), 135-147. doi:10.1016/j.alter.2012. 11.008

Delorme, C. (2015). Enseigner En Contexte d'Intégration Scolaire: Trajectoires Identitaires et Formation Des Enseignants Spécialisés: Centre Suisse de Pédagogie Spécialisée, CSPS, 2. 42-49.

Dion, G., and Tessier, R. (1994). Validation de la traduction de l'Inventaire d'épuisement professionnel de Maslach et Jackson. Can. J. Behav. Sci./Revue Canadienne Des Sci. Du Comportement 26 (2), 210-227. doi:10.1037/0008400x.26.2.210

Doef, M. V., and Maes, S. (2002). Teacher-Specific Quality of Work versus General Quality of Work Assessment: A Comparison of Their Validity Regarding Burnout, (Psycho)Somatic Well-Being and Job Satisfaction. Anxiety, Stress and Coping 15 (4), 327-344. doi:10.1080/1061580021000056500

Done, E. J., and Murphy, M. (2018). The Responsibilisation of Teachers: A Neoliberal Solution to the Problem of Inclusion. Discourse: Stud. Cult. Polit. Edu. 39 (1), 142-155. doi:10.1080/01596306.2016.1243517

Dorman, J. P. (2003). Relationship between School and Classroom Environment and Teacher Burnout: A LISREL Analysis. Soc. Psychol. Edu. 6 (2), 107-127. doi:10.1023/a:1023296126723

Dyrbye, L. N., Massie, F. S., Eacker, A., Harper, W., Power, D., Durning, S. J., Matthew, R. T., Moutier, C., Satele, D., Sloan, J., and Shanafelt, T. D. (2014). Relationship between Burnout and Professional Conduct and Attitudes Among US Medical Students. JAMA 304 (11), 1173-1180. doi:10.1001/jama.2010.1318

Emery, R. A. (2016). La Collaboration Multiprofessionnelle Dans Les Institutions Spécialisées En Lien Avec Les Projets Éducatifs Individualisés Des Élèves: Perceptions, Pratiques Déclarées et Activité Située. Geneva. doi:10.13097/ archive-ouverte/unige: 88570

Emilie, A. F., Keller, R., and Piera, G. (2018). Bedeutung Der Gesundheit von Schulleitenden Und Lehrpersonen Für Die Gesundheit Und Den Bildungserfolg von Schülerinnen Und Schülern. Wissenschaftliche Grundlage Für Das
Argumentarium «Gesundheit Stärkt Bildung». Zürich Und Lausanne: Pädagogische Hochschule.

European Agency for Development in Special Needs Education (2010). Special Needs Education. Country Data 2010. Odense: European Agency for Development in Special Needs Education.

European Agency for Development in Special Needs Education (2012). Special Needs Education Country Data 2012. Odense: European Agency for Development in Special Needs Education.

Fernet, C., Guay, F., Senécal, C., and Austin, S. (2012). Predicting Intraindividual Changes in Teacher Burnout: The Role of Perceived School Environment and Motivational Factors. Teach. Teach. Edu. 28 (4), 514-525. doi:10.1016/j.tate.2011.11.013

Gavish, B., and Friedman, I. A. (2010). Novice Teachers' Experience of Teaching: a Dynamic Aspect of Burnout. Soc. Psychol. Educ. 13 (2), 141-167. doi:10.1007/ s11218-009-9108-0

Ghorpade, J., Lackritz, J., and Singh, G. (2011). Personality as a Moderator of the Relationship between Role Conflict, Role Ambiguity, and Burnout. J. Appl. Soc. Psychol. 41 (6), 1275-1298. doi:10.1111/j.1559-1816.2011.00763.x

Grayson, J. L., and Alvarez, H. K. (2008). School Climate Factors Relating to Teacher Burnout: A Mediator Model. Teach. Teach. Edu. 24 (5), 1349-1363. doi:10.1016/j.tate.2007.06.005

Ho, S. K. (2016). Relationships Among Humour, Self-Esteem, and Social Support to Burnout in School Teachers. Soc. Psychol. Educ. 19 (1), 41-59. doi:10.1007/ s11218-015-9309-7

Houlfort, N., and Sauvé, F. (2010). Santé Psychologique Des Enseignants de La Fédération Autonome de l'enseignement. Canada: École Nationale d'Administration Publique.

Ju, C., Lan, J., Yuan, L., Feng, W., and You, X. (2015). The Mediating Role of Workplace Social Support on the Relationship between Trait Emotional Intelligence and Teacher Burnout. Teach. Teach. Edu. 51, 58-67. doi:10.1016/j.tate.2015.06.001

Kania, M. L., Meyer, B. B., and Ebersole, K. T. (2009). Personal and Environmental Characteristics Predicting Burnout Among Certified Athletic Trainers at National Collegiate Athletic Association Institutions. J. Athletic Train. 44 (1), 58-66. doi:10.4085/1062-6050-44.1.58

Kokkinos, C. M. (2007). Job Stressors, Personality and Burnout in Primary School Teachers. Br. J. Educ. Psychol. 77 (1), 229-243. doi:10.1348/000709905x90344 Laugaa, D., Rascle, N., and Bruchon-Schweitzer, M. (2008). Stress and Burnout Among French Elementary School Teachers: A Transactional Approach. Eur. Rev. Appl. Psychol. 58 (4), 241-251. doi:10.1016/j.erap.2008.09.007

Maillard, W. (2017). Le Service d'intégration Fribourgeois: 18 Ans de Soutien Pédagogique Spécialisé. Berne: CSPS, 14-21.

Maslach, C., and Leiter, M. P. (2016). Understanding the Burnout Experience: Recent Research and its Implications for Psychiatry. World Psychiatry 15 (2), 103-111. doi:10.1002/wps.20311

Maubant, P., and Leclerc, C. (2008). "Le Partenariat Famille-École : À La Recherche de l'improbable Partenariat École-Famille; Origines d'un Malentendu," in Perspectives En Éducation et Formation, 23-36.

Meng, G. (2010). Job Burnout in College Teachers and Management Strategies: Based on the Correlation between Job Burnout and Environment. Wuhan, China: IEEE. doi:10.1109/icmss.2010.5577975

Milteniene, L., and Venclovaite, I. (2012). Teacher Collaboration in the Context of Inclusive Education. Specialusis Ugdymas 27 (2), 99-123.

Näring, G., Briët, M., and Brouwers, A. (2006). Beyond Demand-Control: Emotional Labour and Symptoms of Burnout in Teachers. Work \& Stress 20 (4), 303-315. doi:10.1080/02678370601065182

Otero, L., José, M., Santiago, M. J., Godás, A., Castro, C., Villardefrancos, E., and Ponte, D. (2008). An Integrative Approach to Burnout in Secondary School Teachers: Examining the Role of Student Disruptive Behaviour and Disciplinary Issues. Int. J. Psychol. Psychol. Ther. 8 (2), 259-270.

Özer, N., and Beycioglu, K. (2010). The Relationship between Teacher Professional Development and Burnout. Proced. - Soc. Behav. Sci. 2 (2), 4928-4932. doi:10. 1016/j.sbspro.2010.03.797

Papastylianou, A., Kaila, M., and Polychronopoulos, M. (2009). Teachers' Burnout, Depression, Role Ambiguity and Conflict. Soc. Psychol. Educ. 12 (3), 295-314. doi:10.1007/s11218-008-9086-7

Ponnelle, S. (2008). Contribution Des Déterminants Personnels, Organisationnels et Des Styles d'ajustement Au Stress Dans l'explication de La Santé Subjective Des Enseignants Du Secondaire. L'Orientation Scolaire et Professionnelle 37 (2), 183-213. doi:10.4000/osp.1658 
Rascle, N., Cosnefroy, O., and Quintard, B. (2009). Mesure de La Qualité de Vie Des Enseignants Du Secondaire (QVE) Selon Le Modèle «Job Strain» de Karasek: Une Adaptation Française Du Leiden Quality of Works Questionnaire. Psychol. Du Travail Des Organisations 15 (4), 334-353.

Sam, A. M., Odom, S. L., Tomaszewski, B., Perkins, Y., and Cox, A. W. (2020). Employing Evidence-Based Practices for Children with Autism in Elementary Schools. J. Autism Develop. Disord. doi:10.1007/s10803-020-04706-x

Skaalvik, E. M., and Skaalvik, S. (2007). Dimensions of Teacher Self-Efficacy and Relations with Strain Factors, Perceived Collective Teacher Efficacy, and Teacher Burnout. J. Educ. Psychol. 99 (3), 611-625. doi:10.1037/0022-0663.99.3.611

Skaalvik, E. M., and Skaalvik, S. (2009). Does School Context Matter? Relations with Teacher Burnout and Job Satisfaction. Teach. Teach. Edu. 25 (3), 518-524. doi:10.1016/j.tate.2008.12.006

Squillaci, M. (2020a). “Are Teachers More Affected by Burnout Than Physicians, Nurses and Other Professionals? A Systematic Review of the Literature," in Advances In Intelligent Systems And Computing, 957, 147-155. doi:10.1007/ 978-3-030-20451-8_14

Squillaci, M. (2020b). Relations Parents-Enseignants : Effets Sur Le Burnout Des Enseignants Spécialisés. La Revue Internationale de l'éducation Familiale 47 (1), 151. doi:10.3917/rief.047.0151

Squillaci, M. (2020c). "Does Leadership Matter in Burnout of Special Education Teachers?," in INTED2020 Proceedings, 1, 28. doi:10.21125/inted.2020.0631

Squillaci, M. (2020d). Analysis of the Burnout Levels of Special Education Teachers in Switzerland in Link with a Reform Implementation. Eur. J. Spec. Needs Edu. [Epub ahead of print], 1-10. doi:10.1080/08856257.2020.1809802

Stoeber, J., and Rennert, D. (2008). Perfectionism in School Teachers: Relations with Stress Appraisals, Coping Styles, and Burnout. Anxiety, Stress, \& Coping 21 (1), 37-53. doi:10.1080/10615800701742461
Vercambre, M.-N., Brosselin, P., Gilbert, F., Nerrière, E., and Kovess-Masféty, V (2009). Individual and Contextual Covariates of Burnout: A Cross-Sectional Nationwide Study of French Teachers. BMC Public Health 9 (1), 333. doi:10. 1186/1471-2458-9-333

Wang, Y., Ramos, A., Wu, H., Liu, L., Yang, X., Wang, J., and Wang, L. (2015). Relationship between Occupational Stress and Burnout Among Chinese Teachers: A Cross-Sectional Survey in Liaoning, China. Int. Arch. Occup. Environ. Health 88 (5), 589-597. doi:10.1007/s00420-0140987-9

Wilkerson, K., and Bellini, J. (2006). Intrapersonal and Organizational Factors Associated with Burnout Among School Counselors. J. Couns. Develop. 84 (4), 440-450. doi:10.1002/j.1556-6678.2006. tb00428.x

Zabel, R. H., and Zabel, M. K. (2002). Burnout Among Special Education Teachers and Perceptions of Support. J. Spec. Edu. Leadersh. 15 (2), 67-73.

Zawieja, P., and Guarnieri, F. (2013). Épuisement Professionnel: Approches Innovantes Et Pluridisciplinaires. Paris: Armand Colin.

Conflict of Interest: The authors declare that the research was conducted in the absence of any commercial or financial relationships that could be construed as a potential conflict of interest.

Copyright (c) 2021 Squillaci and Hofmann. This is an open-access article distributed under the terms of the Creative Commons Attribution License (CC BY). The use, distribution or reproduction in other forums is permitted, provided the original author(s) and the copyright owner(s) are credited and that the original publication in this journal is cited, in accordance with accepted academic practice. No use, distribution or reproduction is permitted which does not comply with these terms. 